Article

\title{
Reciprocal Personality Assessment of Both Partners in a Romantic Relationship and Its Correlates to Dyadic Adjustment
}

\author{
Evelyne Smith $\mathbb{D}^{\mathbb{D}}$, Adèle Guérard, Hugues Leduc and Ghassan El-Baalbaki * $\mathbb{D}$ \\ Département de psychologie, Université du Québec à Montréal, CP 8888 Succursale Centre-Ville, Montréal, \\ QC H3C 3P8, Canada; evelynecsmith@gmail.com (E.S.); guerard-lakrout.adele@courrier.uqam.ca (A.G.); \\ leduc.hugues@uqam.ca (H.L.) \\ * Correspondence: el-baalbaki.ghassan@uqam.ca
}

Received: 14 August 2019; Accepted: 20 September 2019; Published: 27 September 2019

\begin{abstract}
This project examines the effects of self- and partner-rated personality and their reciprocal interaction between two partners. Personality in 113 young dating couples was measured with the Five-Factor Model and maladaptive personality trait model of the DSM-5. Partners completed self- and partner-reports of the NEO-FFI-3 and the Personality Inventory for DSM-5 (PID-5) as well as the self-report Dyadic Adjustment Scale (DAS). Three sets of Actor-Partner Interdependence Models (APIMs) were run to estimate actor and partner effects of self-rated personality, partner-rated personality, and of both sets of effects simultaneously in an integrated model. When self- and partner-rating models were examined separately, several significant actor and partner effects were observed. However, the strongest effects were observed in the partner-rating models. When selfand partner-rated personality were examined at the same time, most effects from the self-rating models disappeared. Furthermore, most of the effects as well as the strongest one observed were associated with an individual's perception of their partner's personality, particularly men's perception of women's personality. This study demonstrates the incremental predictive utility of individuals' perception of their partner's personality for explaining their own dyadic adjustment.
\end{abstract}

Keywords: Five-Factor Model; maladaptive personality trait model; dyadic adjustment; APIM

\section{Introduction}

Measures of personality are predictive of several outcomes, including, among others, well-being, spirituality, identity, and community involvement. One's personality is manifested in behavior and attitudes in daily life and especially in interpersonal relationships (Ozer and Benet-Martinez 2006). Longitudinal studies show that measures of personality as early as in childhood can predict adult intimate relationships and even divorce (Roberts and Caspi 2001). Researchers have long tried to find out what qualities people want in a potential life partner. Some researchers study personality and how it is manifested in interpersonal relationships (Ozer and Benet-Martinez 2006). Others look at how personality affects one's perception of the behaviors and attitudes of others, which in turn affects the way one reacts to them (Karney and Bradbury 2000). One approach to answering the initial question is to study how, in romantic relationships, the effects of one's personality and perception of the other's personality are at play between two partners reciprocally (Orth 2013). This interdependent dynamic translates either in healthy or dysfunctional relations.

\subsection{Personality Traits}

Personality theorists have long tried to define the basic common dimensions of personality in order to explain how people differ in terms of their emotional and interpersonal styles. The Five-Factor Model 
(FFM) of personality traits is the most widely used measure of the basic dimensions of personality (McCrae and Costa 2013). There are alternative models and some lexical studies have found support for six rather than five factors, like the HEXACO (Ashton and Lee 2001). However, the replicability of these six factors is not shown across all languages, including English. Furthermore, there is broad support for the FFM. It is therefore the model of choice for this study. While there are some who argue that the lexical approach and use of factor analysis in the early stages of the FFM should be looked at more critically (Block 1995), researchers agree that the five-factor structure nonetheless provides a simple way of describing how people can differ from one another. The five factors have repeatedly been found when using self- and peer-ratings (McCrae and Costa 1987), when studying adults and children (Digman 1997), and in several languages and cultures (McCrae and Costa 1997). Altogether, the FFM has proven to be remarkably robust by providing a replicable phenomenon and a set of tools to be used in research.

Personality traits seem to be dimensional. That is, everyone has varying degrees of each trait rather than simply having them or not, as would be the case in categorical terms. According to the FFM, personality is a multidimensional concept that can be described in terms of five basic dimensions, called Neuroticism (N), Extraversion (E), Openness to Experience (O), Agreeableness (A), and Conscientiousness (C) (McCrae 1991). Although the five traits have been shown to load on pathological extensions of these traits (Guenole 2015), the FFM and measures of the FFM were not designed to capture the negative or extreme poles of the five domains, called negative affect, introversion, closedness, antagonism (or low agreeableness), disinhibition (or low conscientiousness), and psychoticism (high openness) (Krueger and Eaton 2010; Nestadt et al. 2008). There is a need for a model that can measure the negative poles of the five domains as it will provide an alternative perspective and more information about personality.

\subsection{Maladaptive Personality Traits}

A few dimensional models were developed to measure maladaptive personality traits. For example, the Dark Triad is comprised of three maladaptive personalities; Machiavellianism, narcissism, and psychopathy. These personalities are shown to be distinctive constructs and can therefore be measured separately (Paulhus and Williams 2002). The Short Dark Triad (SD3) was therefore developed as a brief questionnaire to measure the Dark Triad (Jones and Paulhus 2014). Another example of a maladaptive personality dimensional model is Hogan and Hogan (2001) derailment factors. The authors identified maladaptive personality characteristics that are associated with career derailment and developed the Hogan Development Survey (HDS, Hogan and Hogan 1997) to measure 11 factors that align with the DSM-IV personality disorders. Although these two examples of maladaptive personality dimensional models are known and used, more recent literature indicates that personality disorder symptomatology is best conceptualized using the maladaptive personality trait model found in Section III of the Diagnostic and Statistical Manual of Mental Disorder-5th edition (DSM-5; Krueger et al. 2012), where disordered personality is described in terms of maladaptive variants of personality traits (Gore and Widiger 2013). Furthermore, the five personality trait domains of the maladaptive personality trait model have been shown to be an extension of the FFM, the chosen model for this study, with negative affect lining up with neuroticism, detachment with introversion, antagonism with low agreeableness, disinhibition with low conscientiousness, and psychoticism with openness (Gore and Widiger 2013). It is important to note that Gore and Widiger (2013) used a sample of undergraduate students and their results are therefore limited to sub-clinical populations. There are several advantages to the dimensional model. Practicing psychologists report that a dimensional rating of personality is more useful than the DSM-IV personality disorders because it communicates information to clients, provides a global description of personality, and can even help with developing effective treatment interventions (Samuel and Widiger 2006). It allows clinicians to describe their patients with normal, adaptive terms rather than restricting the evaluation to maladaptive and dysfunctional ones. By focusing on a more thorough multifaceted description of personality, clinicians 
can identify traits that could help with treatment adherence (Sanderson and Clarkin 2002), it could help to de-stigmatize personality disorders (Hinshaw and Stier 2008), and the traits could be used as a screener for maladaptive personality traits making them much more efficient than semi-structured interviews (Widiger et al. 2009). This shift in thinking captures a more nuanced definition of personality disorders as being the expression of maladaptive variants of personality traits that are present in all individuals (Widiger et al. 2013).

\subsection{Self-Rated Personality and Relationship Satisfaction}

Measures of self-rated personality are related to a range of outcomes, including interpersonal outcomes like romantic relationships (Ozer and Benet-Martinez 2006). How individuals assess their romantic relationships can have an important effect on their quality of life. Several researchers have been interested in the associations between personality traits and relationship satisfaction. Neuroticism is so far the most extensively studied (Daspe et al. 2013) with several studies finding it to be the strongest personality predictor of relationship satisfaction (Bouchard et al. 1999; Karney and Bradbury 1997). Studies of positive personality traits reveal that individuals report higher satisfaction in their relationship when their partner rates high on traits of agreeableness, emotional stability (Botwin et al. 1997), conscientiousness, and extraversion (Malouff et al. 2010). While openness to experience is the least predictive of dyadic adjustment (Caspi et al. 2005; Claxton et al. 2012), one study shows that individuals are happier in their marriages if their spouses report openness traits (Botwin et al. 1997). Moreover, important gender differences in which traits predict satisfaction have been found, but results are inconsistent. While some found that women's neuroticism predicts the satisfaction of both partners (Geist and Gilbert 1996), others found that men's neuroticism better predicts both partners' satisfaction (Karney et al. 1994). Differences in measures and in methodological procedures explain these inconsistent results. While some researchers seek to answer research questions at the dyadic-level, their analyses are conducted at the individual level using simple correlations or multiple regressions. Furthermore, although previous research primarily focuses on married couples and older adults, some studies also interested in dating and engaged couples have found differences across couple types. For instance, self-rated agreeableness and conscientiousness in dating couples are found to better predict satisfaction than in married couples, whereas self-rated extraversion in married couples is shown to have a larger effect on satisfaction than in dating couples (Watson et al. 2000). Finally, only one known study has examined the effects of maladaptive personality traits on couple satisfaction. Results showed that self-rated negative affect and detachment were consistent negative predictors of relationship satisfaction or adjustment, whereas disinhibition and psychoticism were less consistently associated, and antagonism was unrelated (Decuyper et al. 2018).

\subsection{Importance of Partner-Reports}

While many studies on personality are now examining personality traits of both partners involved in romantic relationships, most only use self-reported inventories (Bouchard et al. 1999; Robins et al. 2000) with very few using partner-reports (partners reporting how they perceive their mate's personality; Kosek 1996; Watson et al. 2000). While there can be overlap with regard to personality perceptions (self-report and partner-report) in couples who have known each other for long periods of time, partner-reports do provide valuable information that is often not captured in the use of self-reports alone. How an individual perceives their partner has a strong impact on their satisfaction (Murray et al. 1996). In fact, studies show that correlations between a participant's dyadic adjustment and their rating of their partner's personality (partner-report) display stronger effects than self-reported personality on dyadic adjustment (Altmann et al. 2013; Brock et al. 2016; Schaffhuser et al. 2014; Schaffhuser et al. 2016). There are differences across couple types and gender. For example, an individual's rating of their partner's openness to experience is more important for a man's satisfaction in dating couples and for a woman's satisfaction in married couples (Orth 2013). In terms of maladaptive personality traits, one study shows that partner-rated negative affect, 
detachment, disinhibition, and psychoticism were consistent negative predictors of relationship satisfaction or adjustment, whereas partner-rated antagonism was only associated with women's dyadic adjustment (Decuyper et al. 2018). Adding partner-reports of personality assessments can help to corroborate individuals' self-reported personality, provide another perspective with regard to the interpersonal effects that dysfunctional personality can have, and can provide crucial data about the effects of personality on dyadic adjustment (Oltmanns et al. 1998; South et al. 2008).

\subsection{Interdependence}

Dyadic data is unique because it comes from two partners from the same couple. That is, the partners are interdependent. When studying interdependence, it is important to consider that an individual's personality predicts their own dyadic adjustment (actor effects), and it also predicts their partner's dyadic adjustment (partner effects; Dyrenforth et al. 2010; Robins et al. 2000). In order to consider interdependent effects in statistical analyses, researchers are using the Actor-Partner Interdependence Model (APIM, Kashy and Kenny 2000; Kenny 1996). Researchers have long been interested in the actor effects of personality on satisfaction. However, there is far less research and inconsistent results with regard to the partner effects of personality on couple satisfaction. Furthermore, most studies use correlation analyses which do not consider the interdependent nature of couple data (Decuyper et al. 2012; Watson et al. 2000). Some studies using the APIM model have found that self-reported extraversion, agreeableness, and neuroticism have important partner effects, and that all partner-reported Big Five traits also have strong partner effects (Furler et al. 2014; Orth 2013). One study examining the effects of maladaptive personality traits on couple satisfaction using both self- and partner-reports as well as the APIM found significant negative partner effects for partner-rated negative affect on both partners. Furthermore, the researchers found robust partner effects for detachment on both men and women's relationship satisfaction (Decuyper et al. 2018).

\subsection{Integrating Personality and Dyadic Adjustment Assessments with Interdependence}

When studying the role that personality plays in romantic relationships, it is important to consider both partners' perspectives. As previously discussed, the positive personality traits of the FFM tend to have positive effects on dyadic adjustment, whereas neuroticism tends to have a negative effect on dyadic adjustment. With regard to the negative personality traits of the maladaptive personality trait model, research shows that they have a negative effect on dyadic adjustment. While these trends are not surprising, it is important for researchers to consider the interdependent nature of couple data, that is, the effect that personality has on both partners' dyadic adjustment. When the assumption of independence is violated in the analysis of dyadic data, the test statistic and the degrees of freedom for the test statistic are inaccurate, and its statistical significance is biased. Therefore, researchers who study personality and couples use both self- and partner-reports of personality and appropriate statistical procedures like the APIM to capture the truly interpersonal nature of personality relationships.

\subsection{This Study}

The Actor-Partner Interdependence Model (Cook and Kenny 2005) and structural equation model analyses were used to verify if, as hypothesized, (1) positive factors of the Five-Factor Model (extraversion, openness to experience, agreeableness, and conscientiousness) through actor-partner assessments of personality traits have positive effects on both partners' self-reported dyadic adjustment. The same analyses were run with maladaptive personality traits to verify if, as hypothesized, (2) the presence of dysfunctional personality features as measured by the maladaptive personality trait model has a negative effect on both partners' self-reported dyadic adjustment. Furthermore, it is hypothesized that (3) an individual's rating of their partner's personality (partner-report) has a stronger effect on their dyadic adjustment than their self-reported personality. While most studies examine self-rated and partner-rated personality in separate models, this study will also simultaneously examine both in an integrated APIM model to study the incremental predictive utility of partner-ratings. Finally, 
the role of gender in the association between personality and dyadic adjustment will be explored. Previous research has shown gender differences with regard to the effect that personality has on dyadic adjustment, but results have often been inconsistent due to methodological issues (Geist and Gilbert 1996; Karney et al. 1994). This is the first known study to examine the effects of both partners' personality on dyadic adjustment using appropriate statistical procedures and younger couples. Therefore, the examination of the role of gender in this study is exploratory in nature.

\section{Method}

\subsection{Participants}

Web-based questionnaires on SurveyMonkey were used to collect the data. Participants completed the questionnaires at home. Two hundred twenty-six participants (113 heterosexual couples) were recruited through Canadian universities and in the community using online advertising (Kijiji), social media (Facebook), and posters. This study chose to focus on heterosexual couples to ensure a homogeneous sample. Individuals were recruited (a) if both partners were willing to participate, (b) if both partners were between 21 and 30 years old, (c) if they had been in their current relationship since at least 6 months (only dating couples were used for this article), (d) if they had been living together for at least 6 months, and (e) if both partners were comfortable enough in English to answer a battery of questionnaires. The age of the participants was chosen based on the requirement that couples be in a committed relationship, which occurs in the fourth phase of romantic development, the bonding phase, and which typically occurs at age 21 (Seiffge-Krenke 2003). Furthermore, studies demonstrate developmental changes in personality before the age of 30 (Roberts et al. 2006). With previous research mainly focused on older couples, this study will examine personality and dyadic adjustment associations in individuals still going through maturational changes and will add to a scarce body of knowledge for this population. Moreover, personality traits have been shown to change over lifetime and they should be treated as developmental constructs (Roberts and Caspi 2001). As such, in order to map out these developmental changes, this study has chosen to initially focus on younger couples. Participants were informed about the purpose and procedure of the study. Confidentiality was explained to them. Once participants provided informed consent, they each received unique links to the questionnaires. Partners were told not to consult each other while completing the questionnaires. Once participants completed the study, they received \$5 (\$10/couple) in exchange for participation in the study. For sample characteristics, please refer to the results section.

\subsection{Measures}

\subsubsection{General Socio-Demographic Information}

The authors developed a socio-demographic questionnaire with 27 items. It verified that participants were eligible to participate, and also sampled information about their mother tongue and the language spoken between partners, previous relationships, whether participants came from a single- or double-parent household, their occupation, their ethnicity, their country of origin, whether they or their partner was diagnosed with a psychiatric illness and whether they took any medication, and whether they or their partner use any substance. Each partner completed the socio-demographic questionnaire. The inclusion criteria and the participants' occupations were used in this study.

\subsubsection{Personality (Self- and Partner-Reports)}

The 60-item NEO-FFI-3 (McCrae and Costa 2010) was used to assess the Big Five personality traits. It assesses the five personality traits of the five-factor model of personality (neuroticism, extraversion, openness to experience, agreeableness, conscientiousness). Each scale includes 12 items which are rated on a 5 -point Likert scale $(1=$ strongly disagree, $5=$ strongly agree). These items assess whether the participant considers the statement to be representative of themselves. Each participant completed 
two inventories; a first inventory about their own personality (self-report; form S) and a second inventory about their partner's personality (partner-report; form R). The computer software was used to transform the partners' scores on each trait into T scores. These T scores were based on the adult American norms in the NEO-FFI-3 manual (McCrae and Costa 2010).

The maladaptive personality traits were assessed with the 25-item Personality Inventory for DSM-5-Brief Form (PID-5-BF; Krueger et al. 2013). It was developed to measure the five maladaptive personality traits (negative affect, detachment, psychoticism, antagonism, disinhibition). Each domain includes five items rated on a 4-point Likert scale ( $0=$ very false or often false, $3=$ very true or often true). The items assess whether the participant considers the statement to be representative of themselves. Each participant completed two inventories; a first inventory about their own personality (self-report, Adult version) and a second inventory about their partner's personality (partner-report, brief form). With permission from the authors of the PID-5, the partner-report was created by using the same structure as the original 220-item PID-5 informant report. Each item on the self-report PID-5-BF was reformulated using the third person singular. Reliability analysis was carried out on each trait domain each comprising five items. Reliability coefficients $(\alpha)$ indicated adequate internal consistency for each of the five domain scales (Negative Affect $\alpha=0.75$; Detachment $\alpha=0.61$; Antagonism $\alpha=$ 0.74; Disinhibition $\alpha=0.78$; Psychoticism $\alpha=0.78$ ). These results are similar to those found for the PID-5-BF in previous studies (Anderson et al. 2018; Bach et al. 2016; Fossati et al. 2017). The partners' scores on each trait were transformed to T scores using norms published by the authors of the PID-5 (Krueger et al. 2012; Markon et al. 2013).

\subsubsection{Dyadic Adjustment (Self-Report)}

The 32-item Dyadic Adjustment Scale (DAS; Spanier 1976) was used to assess dyadic adjustment. The DAS is a widely used instrument developed to assess the quality of adjustment in couples via a self-report format. It is comprised of four subscales; consensus, satisfaction, cohesion, and affectional expression. The DAS has different scales which assess how much each statement is representative of the respondent. For the purpose of this study, the subscales were combined into a single overall index of dyadic adjustment (Spanier 1976). Women and men's T scores could then be interpreted using the published guidelines (Spanier 1976) to determine whether they were well adjusted (T score $>45$ ) or whether there were concerns (T score $<45$ ).

\subsection{Statistical Analyses}

Partners' scores on each questionnaire were transformed to T scores. The NEO-FFI-3 (McCrae and Costa 2010) computer software automatically chose the T score as its standardized score. Therefore, the PID-5 (Krueger et al. 2013) and DAS (Spanier 1976) scores were also transformed to T scores for uniformity. In each case, $\mathrm{T}$ scores were calculated using American norms published by the authors of each questionnaire. While the DAS has Canadian norms (Baillargeon et al. 1986), the overall index of dyadic adjustment does not differ from that published by Spanier (1976). Furthermore, the other questionnaires do not have Canadian norms. Therefore, in order to compare scores across all questionnaires, American norms were used.

Participants were considered distinguishable by their gender. The members of a distinguishable dyad can be differentiated on a within-dyad variable (e.g., gender) that has substantial meaning to distinguish members from one another (Kenny and Cook 1999). Several sets of Actor-Partner Interdependence Models (APIM, Kenny et al. 2006) were tested using structural equation modeling. APIMs consider the couple the unit of analysis. Therefore, a dyad-level dataset was used where the unit of analysis is the couple. Furthermore, APIMs consider the interdependent effects between the two partners, because they account for the actor and partner effects. Three sets of APIMs were analyzed in order to study the different personality effects on each partner's dyadic adjustment. All models represent saturated models. 
The first set of APIMs involved self-rated personality. One personality trait was analyzed at a time in each model. Both partners' dyadic adjustment was predicted by each partner's self-rated personality (self-rating models). Therefore, ten models that estimated self-rated personality actor and partner effects were analyzed (one for each Big Five trait and maladaptive trait) (see Figure 1 for the self-rating model).
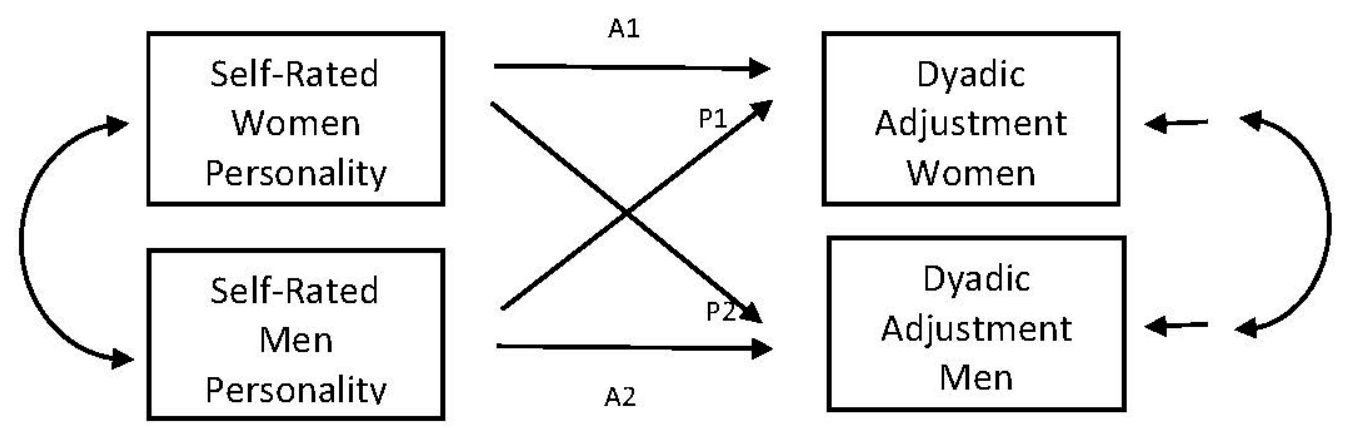

Figure 1. Self-rating model. Each partner's dyadic adjustment is predicted by each partner's self-rated personality.

The second set of APIMs involved partner-rated personality. The analyses were run the same as in the first set of analyses. Therefore, this second set of APIMs included ten models that estimated partner-rated personality actor and partner effects (one for each Big Five trait and maladaptive trait) (see Figure 2 for the partner-rating model).

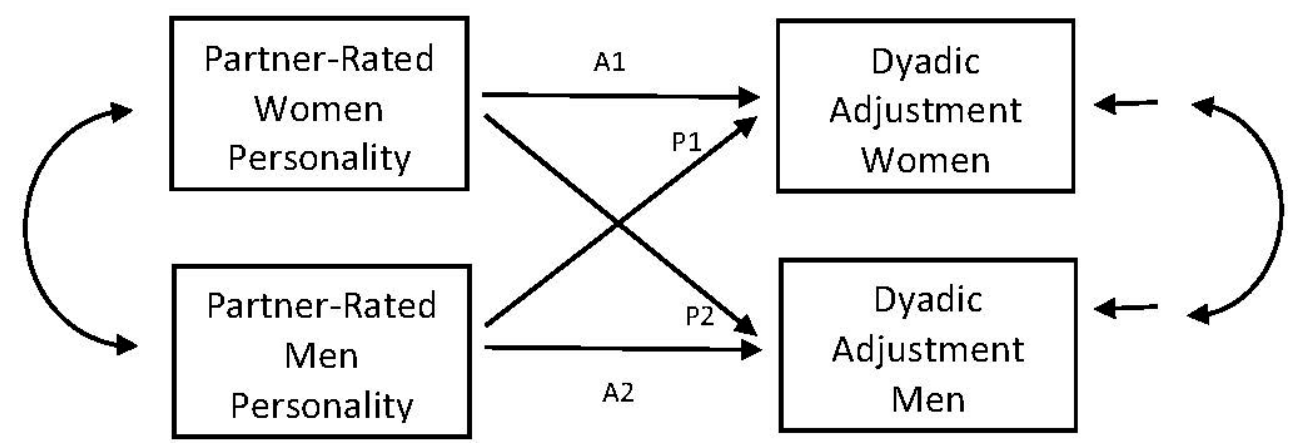

Figure 2. Partner-rating model. Each partner's dyadic adjustment is predicted by each partner's partner-rated personality. The label "Partner-Rated" represents the partner's rating of that individual's personality (e.g., partner-rated women represents the men's rating of the women's personality).

The third set of analyses consisted of both self- and partner-rated personality simultaneously analyzed in an integrated model. This allows for the assessment of the effects of partner-rated personality above and beyond self-rated personality (and vice versa). Models were run separately for each Big Five trait and maladaptive trait. Therefore, this set of analyses included ten models that estimated self- and partner-rated personality actor and partner effects (one for each Big Five trait and maladaptive trait) (see Figure 3 for the integrated model).

Analyses were conducted using MPlus 8.0 (Muthén and Muthén 2017). An alpha level of 0.05 was used for all tests of statistical significance. The estimator was specified as MLR, a maximum likelihood estimation method with standard errors and a chi-square test statistic that are robust to non-normality. 


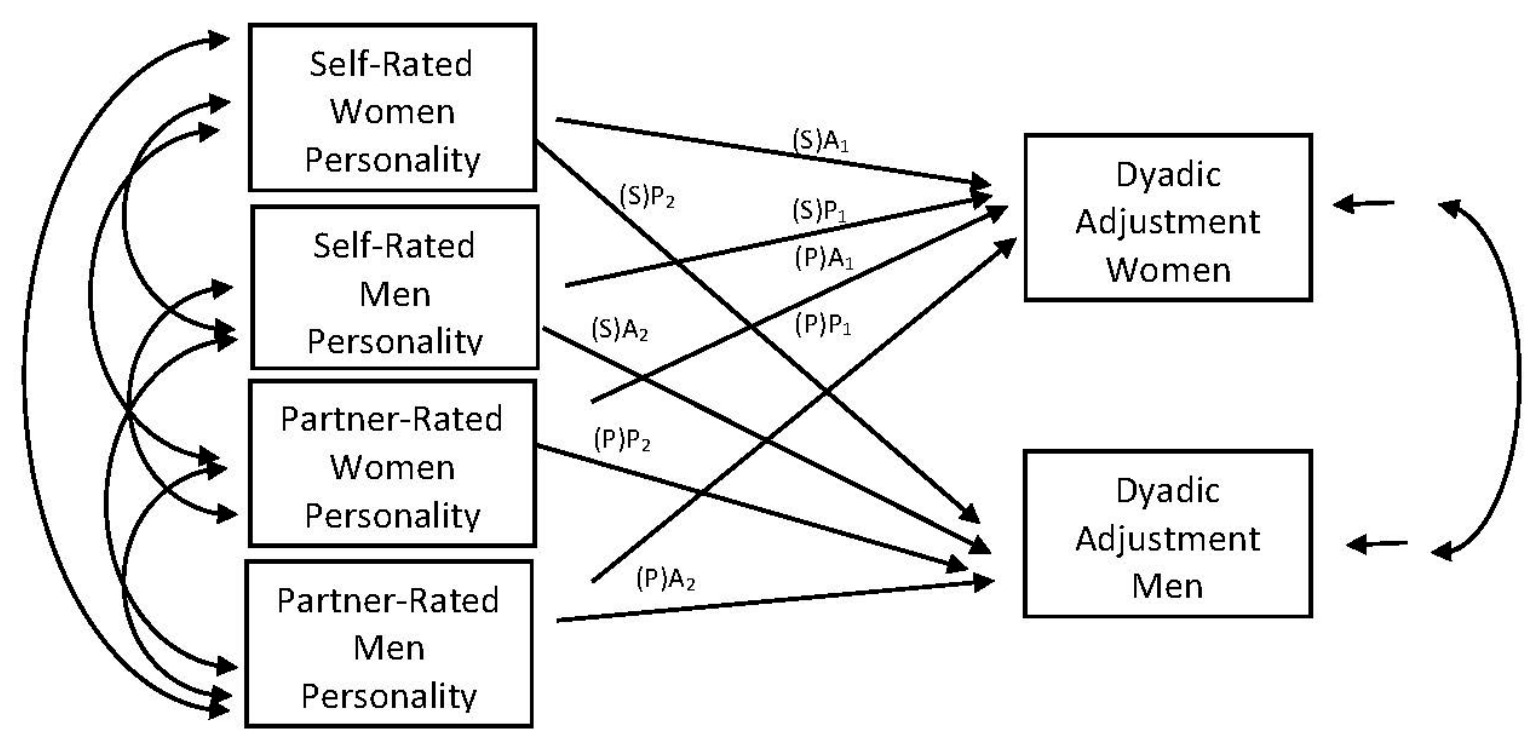

Figure 3. Model specification for the integrated models including self- and partner-rated personality.

\section{Results}

\subsection{Sample Characteristics}

The sample includes 113 couples. Female participants had a mean age of $24.2(S D=2.3$, range $=21$ to 30) and male participants had a mean age of $25.1(S D=2.6$, range $=21$ to 30). Length of relationship ranged from eight to 120 months $(M=34.9, S D=23.1)$ and length of cohabitation ranged from six to 86 months $(M=17.8, S D=14.5)$. Of the participants, $70.8 \%$ of the women and $50.4 \%$ of the men were students, $24.8 \%$ of the women and $46.9 \%$ of the men were employed, and $4.4 \%$ of the women and $2.7 \%$ of the men were unemployed.

\subsection{Descriptive Analyses}

For all measures, please refer to Table 1 for the means and standard deviations of the $\mathrm{T}$ scores, and Hedges' $\mathrm{g}$ effect sizes with their $95 \% \mathrm{CI}$ centered on mean differences for the paired-sample $\mathrm{t}$-tests for male and female partners. Women's dyadic adjustment $(M=49.75, S D=6.90)$ was non-significantly higher than men's $(M=48.83, S D=7.09)$. Using the interpretive guidelines (Spanier 1976), it appears that, on average, both women and men are well adjusted in their relationship. On closer inspection, 87 women report being well adjusted (T score $>45$ ) and 85 men report the same. Women and men differed significantly on some self-rated and partner-rated traits. Women scored significantly higher on self-rated conscientiousness $(t(112)=2.21, p=.029,95 \% \mathrm{CI}[0.31,5.60])$ and negative affect $(t(112)$ $=6.98, p<.001,95 \% \mathrm{CI}[9.91,17.76])$, and on partner-rated (as they were rated by men) neuroticism $(t(112)=2.59, p=.011,95 \%$ CI $[1.08,8.02])$, conscientiousness $(t(112)=2.59, p=.011,95 \%$ CI [0.93, 6.95]), and negative affect $(t(112)=4.16, p<.001,95 \% \mathrm{CI}[3.31,9.33])$. Men scored significantly higher on self-rated detachment $(t(112)=-2.10, p=.038,95 \% \mathrm{CI}[-4.33,-0.13])$ and disinhibition $(t(112)=$ $-2.83, p=.006,95 \%$ CI $[-13.85,-2.43])$. Nonindependence for distinguishable dyads was computed using the partial Pearson product-moment correlation while controlling for the predictor variables. Partners' dyadic adjustment was significantly correlated, $r=.49, p<.001$. Therefore, women and men in this sample were significantly interdependent with regard to their dyadic adjustment. (For all other correlations, please refer to the Supplemental data. These correlations were not used for the interpretation of the results in this study.) 
Table 1. Means and standard deviations for T scores, and Hedges' $\mathrm{g}$ effect sizes with their 95\% CI for mean differences for the paired-sample $t$-tests for male and female partners.

\begin{tabular}{|c|c|c|c|c|c|}
\hline & Female & Male & & & \\
\hline Measure & $M(S D)$ & $M(S D)$ & $p$ & $95 \% \mathrm{CI}$ & Hedges' g \\
\hline \multicolumn{6}{|l|}{ Self-Report } \\
\hline $\mathrm{N}$ & $54.88(11.11)$ & $52.76(10.04)$ & .109 & $(-0.48,7.71)$ & .20 \\
\hline $\mathrm{E}$ & $51.75(12.02)$ & $52.87(11.25)$ & .431 & $(-3.91,1.68)$ & .10 \\
\hline $\mathrm{O}$ & $58.65(10.93)$ & $59.49(9.97)$ & .476 & $(-3.14,1.47)$ & .08 \\
\hline $\mathrm{A}$ & $46.72(10.11)$ & $49.39(11.06)$ & .056 & $(-5.42,0.75)$ & .69 \\
\hline C & $49.19(10.23)$ & $46.23(11.74)$ & .029 & $(0.31,5.60)$ & .27 \\
\hline Nega & $60.60(16.28)$ & $46.76(14.25)$ & .000 & $(9.91,17.76)$ & .90 \\
\hline Det & $49.03(9.55)$ & $51.26(10.16)$ & .038 & $(-4.33,-0.13)$ & .23 \\
\hline Psy & $62.93(19.14)$ & $62.12(15.23)$ & .689 & $(-3.18,4.79)$ & .05 \\
\hline Ant & $51.40(12.48)$ & $50.94(12.72)$ & .759 & $(-2.48,3.39)$ & .04 \\
\hline Dis & $41.16(20.65)$ & $49.30(24.00)$ & .006 & $(-13.85,-2.43)$ & .36 \\
\hline Partner-Report & Men's View of Women & Women's View of Men & & & \\
\hline $\mathrm{N}$ & $56.16(11.79)$ & $51.61(12.89)$ & .011 & $(1.08,8.02)$ & .37 \\
\hline $\mathrm{E}$ & $51.08(12.62)$ & $52.55(12.07)$ & .405 & $(-4.95,2.01)$ & .12 \\
\hline $\mathrm{O}$ & $59.28(10.97)$ & $60.83(12.01)$ & .266 & $(-4.29,1.20)$ & .13 \\
\hline A & $50.43(10.80)$ & $51.75(11.90)$ & .404 & $(-4.44,1.80)$ & .12 \\
\hline C & 52.35 (10.39) & $48.41(11.00)$ & .011 & $(0.93,6.95)$ & .37 \\
\hline Nega & $58.92(11.45)$ & $52.6(11.15)$ & .000 & $(3.31,9.33)$ & .56 \\
\hline Det & $51.02(9.92)$ & $50.77(9.50)$ & .835 & $(-2.12,2.61)$ & .03 \\
\hline Psy & $56.30(13.96)$ & $55.26(12.83)$ & .531 & $(-2.24,4.31)$ & .08 \\
\hline Ant & $46.91(8.26)$ & $48.00(9.61)$ & .302 & $(-3.17,0.99)$ & .12 \\
\hline Dis & $52.37(11.72)$ & $51.72(11.83)$ & .667 & $(-2.35,3.65)$ & .06 \\
\hline DAS & $49.75(6.90)$ & $48.83(7.09)$ & .177 & $(-0.42,2.25)$ & .13 \\
\hline
\end{tabular}

Note. The label "Partner-Report" represents the partner's rating of that individual's personality (e.g., partner-report for women represents the men's rating of the women's personality). $\mathrm{N}=$ neuroticism; $\mathrm{E}=$ extraversion; $\mathrm{O}=$ openness; $\mathrm{A}=$ agreeableness $; \mathrm{C}=$ conscientiousness; $\mathrm{Nega}=$ negative affect; Det $=$ detachment; Psy $=$ psychoticism; Ant $=$ antagonism; Dis = disinhibition. Data in bold represent statistically significant values, $p<.05$.

\subsection{Self-Rated Personality and Dyadic Adjustment}

In the first set of analyses (see Figure 1), self-rated personality actor and partner effects on dyadic adjustment were estimated for each of the Big Five and maladaptive personality traits while controlling for each partner's age, and the length of the relationship and cohabitation. A summary of the results is in Table 2.

Positive actor effects were found for both women and men for agreeableness and conscientiousness. A positive actor effect was found for men for extraversion. These results support Hypothesis 1 . Negative actor effects were found for both women and men for neuroticism, detachment, and psychoticism. Negative actor effects were found for women for negative affect and disinhibition. These results support Hypothesis 2. When women and men viewed themselves as high in agreeableness or conscientiousness, they reported greater dyadic adjustment. Men who viewed themselves as high in extraversion reported greater dyadic adjustment. However, when women and men viewed themselves as high in neuroticism, detachment, or psychoticism, they reported lower dyadic adjustment. When women viewed themselves as high in negative affect or disinhibition, they reported lower dyadic adjustment. Effect sizes were small to medium ranging from $|\beta|=.18(t(106)=2.21, p=.027)$ to $|\beta|=.34(t(106)=$ $-3.71, p<.001$ ) (see Table 2) (Cohen 1988). No actor effects were found for openness or antagonism.

Positive partner effects were found for women for conscientiousness and for men for agreeableness. These results support Hypothesis 1. Negative partner effects were found for both women and men for neuroticism and antagonism. Negative partner effects were found for men for negative affect, detachment, and psychoticism. These results support Hypothesis 2. Therefore, women rated their dyadic adjustment as being higher when their partner viewed themselves as high in conscientiousness. Men rated their dyadic adjustment as being higher when their partner viewed themselves as high 
in agreeableness. However, women and men reported lower dyadic adjustment when their partner viewed themselves as high in neuroticism or antagonism. Men reported lower dyadic adjustment when their partner viewed themselves as high in negative affect, detachment, or psychoticism. Effect sizes were small to medium ranging from $|\beta|=.18(t(106)=-2.04, p=.042)$ to $|\beta|=.44(t(106)=5.90, p<.001)$ (see Table 2; Cohen 1988). No partner effects were found for extraversion, openness, or disinhibition.

Table 2. Results from self-rated models.

\begin{tabular}{|c|c|c|c|c|c|c|c|c|c|c|c|c|}
\hline \multicolumn{13}{|c|}{ Self-Rated Model } \\
\hline \multirow[b]{2}{*}{ Scale } & \multicolumn{6}{|c|}{ Female DAS } & \multicolumn{6}{|c|}{ Male DAS } \\
\hline & A1 & $t$ & $p$ & P1 & $t$ & $p$ & A2 & $t$ & $p$ & P2 & $t$ & $p$ \\
\hline $\mathrm{N}$ & -.302 & -3.12 & .002 & -.245 & -2.63 & .009 & -.193 & -2.25 & .025 & -.222 & -2.47 & .014 \\
\hline $\mathrm{E}$ & .111 & 1.15 & .252 & .001 & 0.02 & .988 & .202 & 2.36 & .018 & .071 & 0.81 & .418 \\
\hline $\mathrm{O}$ & .160 & 1.57 & .116 & .102 & 1.20 & .229 & .080 & 0.92 & .360 & .102 & 0.95 & .341 \\
\hline $\mathrm{A}$ & .227 & 2.39 & .017 & .114 & 1.10 & .270 & .182 & 2.21 & .027 & .436 & 5.90 & .000 \\
\hline C & .206 & 2.00 & .045 & .262 & 3.09 & .002 & .285 & 3.33 & .001 & .106 & 1.00 & .320 \\
\hline Nega & -.243 & -2.99 & .003 & -.158 & -1.59 & .111 & -.155 & -1.59 & .111 & -.253 & -2.85 & .004 \\
\hline Det & -.275 & -2.96 & .003 & -.054 & -0.52 & .606 & -.208 & -2.32 & .021 & -.187 & -2.07 & .038 \\
\hline Psy & -.341 & -3.71 & .000 & -.055 & -0.56 & .578 & -.216 & -2.51 & .012 & -.289 & -2.79 & .005 \\
\hline Ant & -.135 & -1.50 & .135 & -.184 & -2.04 & .042 & -.087 & -0.81 & .417 & -.346 & -3.91 & .000 \\
\hline Dis & -.301 & -3.12 & .002 & -.048 & -0.52 & .601 & -.115 & -1.49 & .135 & -.112 & -1.01 & .312 \\
\hline
\end{tabular}

Note. Beta coefficients are standardized. Data in bold represent statistically significant values, $p<.05 . \mathrm{A} 1=$ female actor effect; $\mathrm{P} 1$ = female partner effect; $\mathrm{A} 2$ = male actor effect; $\mathrm{P} 2$ = male partner effect; $\mathrm{N}$ = neuroticism; $\mathrm{E}=$ extraversion; $\mathrm{O}$ = openness; $\mathrm{A}$ = agreeableness; $\mathrm{C}$ = conscientiousness; $\mathrm{Nega}=$ negative affect; $\mathrm{Det}=$ detachment; Psy $=$ psychoticism; Ant = antagonism; Dis $=$ disinhibition .

To test whether actor and partner effects differed among women and men, their corresponding actor and partner estimates were constrained to be invariant and the chi-square difference test was examined. Constraining the actor and partner estimates did not decrease model fit. Therefore, the actor and partner effects for both partners do not differ on the ten self-reported traits.

To test whose self-rated personality had the largest effect on each partner's dyadic adjustment, actor and partner estimates for each trait for one partner's dyadic adjustment were constrained to be invariant and the chi-square difference test was examined. Constraining men's actor and partner estimates for agreeableness to be invariant significantly decreased model fit $\left(\Delta \chi^{2}(\Delta d f=5)=11.42\right.$, $p=.044)$. Women's self-rated agreeableness had a significantly larger effect on men's dyadic adjustment than men's self-rated agreeableness had on their own dyadic adjustment.

\subsection{Partner-Rated Personality and Dyadic Adjustment}

In the second set of analyses (see Figure 2), partner-rated personality actor and partner effects on dyadic adjustment were estimated for each of the Big Five traits and maladaptive personality traits while controlling for each partner's age, and the length of the couples' relationship and cohabitation. Please refer to Table 3 for a summary of the results. In these models, actor paths (A1 and A2) represent the association between the partner's view of the individual's personality ("how my partner sees $\mathrm{me}^{\prime \prime}$ ) and that individual's own dyadic adjustment. The partner paths (P1 and P2) represent the relationship between the individual's view of their partner ("how I see my partner") and their own dyadic adjustment.

Positive actor effects were found for both women and men for conscientiousness. Positive actor effects were found for women for openness, and for men for extraversion and agreeableness. These results support Hypothesis 1. Negative actor effects were found for both partners for neuroticism, negative affect, and antagonism. Negative actor effects were found for women for disinhibition, and for men for detachment and psychoticism. These results support Hypothesis 2. Therefore, when women were viewed as high in openness or conscientiousness, they reported greater dyadic adjustment. Men who were viewed as high in extraversion, agreeableness, or conscientiousness 
reported greater dyadic adjustment. When women and men were viewed as high in neuroticism, negative affect, or antagonism, they reported lower dyadic adjustment. When women were viewed as high in disinhibition, they reported lower dyadic adjustment. When men were viewed as high in detachment or psychoticism, they reported lower dyadic adjustment. Effect sizes were small to medium ranging from $|\beta|=.15(t(106)=-2.10, p=.036)$ to $|\beta|=.33(t(106)=-4.07, p<.001)$ (see Table 3; Cohen 1988).

Positive partner effects were found for both women and men for agreeableness and conscientiousness. Positive partner effects were found for men for extraversion and openness. These results support Hypothesis 1. Negative partner effects were found for both women and men for neuroticism, negative affect, detachment, psychoticism, antagonism, and disinhibition. These results support Hypothesis 2. Therefore, when women and men viewed their partner as being high in agreeableness or conscientiousness, they reported greater dyadic adjustment. Men who rated their partner as being high in extraversion or openness reported greater dyadic adjustment. When women and men rated their partner as high in neuroticism, negative affect, detachment, psychoticism, antagonism, or disinhibition, they reported lower dyadic adjustment. Effect sizes were small to large ranging from $|\beta|=.22(t(106)=2.45, p=.014)$ to $|\beta|=.55(t(106)=9.41, p<.001)$ (see Table 3; Cohen 1988).

Table 3. Results from partner-rated models.

\begin{tabular}{|c|c|c|c|c|c|c|c|c|c|c|c|c|}
\hline \multicolumn{13}{|c|}{ Partner-Rated Model } \\
\hline \multirow[b]{2}{*}{ Scale } & \multicolumn{6}{|c|}{ Female DAS } & \multicolumn{6}{|c|}{ Male DAS } \\
\hline & A1 & $t$ & $p$ & P1 & $t$ & $p$ & A2 & $t$ & $p$ & P2 & $t$ & $p$ \\
\hline $\mathrm{N}$ & -.325 & -4.07 & .000 & -.353 & -4.74 & .000 & -.158 & -2.20 & .028 & -.471 & -6.41 & .000 \\
\hline $\mathrm{E}$ & .060 & 0.62 & .534 & .048 & 0.48 & .631 & .189 & 2.39 & .017 & .332 & 4.06 & .000 \\
\hline $\mathrm{O}$ & .227 & 2.53 & .011 & .175 & 1.82 & .070 & .077 & 0.94 & .346 & .399 & 4.73 & .000 \\
\hline $\mathrm{A}$ & .095 & 1.08 & .280 & .290 & 3.49 & .000 & .189 & 2.48 & .013 & .485 & 8.02 & .000 \\
\hline $\mathrm{C}$ & .277 & 3.94 & .000 & .472 & 6.86 & .000 & .259 & 3.57 & .000 & .554 & 9.41 & .000 \\
\hline Nega & -.324 & -4.04 & .000 & -.328 & -3.50 & .000 & -.211 & -2.35 & .019 & -.438 & -6.33 & .000 \\
\hline Det & -.122 & -1.38 & .167 & -.276 & -3.52 & .000 & -.152 & -2.10 & .036 & -.459 & -6.21 & .000 \\
\hline Psy & -.073 & -0.66 & .512 & -.369 & -3.86 & .000 & -.203 & -2.52 & .012 & -.337 & -3.91 & .000 \\
\hline Ant & -.248 & -2.21 & .027 & -.229 & -2.15 & .032 & -.280 & -3.24 & .001 & -.387 & -5.07 & .000 \\
\hline Dis & -.323 & -4.18 & .000 & -.222 & -2.45 & .014 & -.140 & -1.62 & .105 & -.433 & -6.26 & .000 \\
\hline
\end{tabular}

Note. Beta coefficients are standardized. Data in bold represent statistically significant values, $p<.05 . \mathrm{A} 1=$ female actor effect; $\mathrm{P} 1$ = female partner effect; $\mathrm{A} 2$ = male actor effect; $\mathrm{P} 2$ = male partner effect; $\mathrm{N}$ = neuroticism; $\mathrm{E}=$ extraversion; $\mathrm{O}=$ openness; $\mathrm{A}=$ agreeableness $\mathrm{C}$ = conscientiousness; $\mathrm{Nega}=$ negative affect; $\mathrm{Det}=$ detachment; Psy $=$ psychoticism; Ant $=$ antagonism $;$ Dis $=$ disinhibition .

To test whether actor and partner effects differed among men and women, their corresponding actor and partner estimates were constrained to be invariant and the chi-square difference test was examined. Constraining the actor and partner estimates did not decrease model fit. Therefore, the actor and partner effects for both partners do not differ on the ten partner-reported traits.

To test whose partner-rated personality had the largest effect on each partner's dyadic adjustment, actor and partner estimates for each trait for one partner's dyadic adjustment were constrained to be invariant and the chi-square difference test was examined. Setting men's actor and partner estimates for agreeableness or conscientiousness to be invariant significantly decreased model fit $\left(\Delta \chi^{2}(\Delta d f=5)\right.$ $\left.=17.24, p=.004 ; \Delta \chi^{2}(\Delta d f=5)=19.06, p=.002\right)$. Therefore, men's dyadic adjustment appears to be influenced more by how agreeable or conscientious they think their partner is than by what women think of their agreeableness or conscientiousness.

\subsection{Integrated Model with Both Self- and Partner-Rated Personality and Dyadic Adjustment}

The third set of analyses (see Figure 3) consisted of actor and partner effects of self- and partner-rated personality on dyadic adjustment being estimated for each of the Big Five traits and maladaptive 
personality traits while controlling for each partner's age, and the length of the relationship and cohabitation. A summary of the results is in Table 4.

Table 4. Results from integrated models.

\begin{tabular}{|c|c|c|c|c|c|c|c|c|c|c|c|c|}
\hline \multicolumn{13}{|c|}{ Female DAS } \\
\hline Scale & (S)A1 & $t$ & $p$ & (P)A1 & $t$ & $p$ & (S)P1 & $t$ & $p$ & (P)P1 & $t$ & $p$ \\
\hline $\mathrm{N}$ & -.180 & -1.75 & .079 & -.207 & -1.93 & .053 & -.120 & -1.09 & .275 & -.260 & -2.63 & .009 \\
\hline $\mathrm{E}$ & .152 & 1.16 & .247 & -.040 & -0.30 & .766 & -.062 & -0.48 & .633 & .082 & 0.59 & .558 \\
\hline $\mathrm{O}$ & .014 & 0.12 & .903 & .226 & 2.30 & .021 & -.029 & -0.29 & .774 & .188 & 1.59 & .112 \\
\hline A & .199 & 1.72 & .085 & -.005 & -0.05 & .963 & -.035 & -0.26 & .793 & .274 & 2.38 & .018 \\
\hline $\mathrm{C}$ & .054 & 0.47 & .636 & .252 & 2.81 & .005 & -.005 & -0.05 & .957 & .461 & 5.30 & .000 \\
\hline Nega & -.053 & -0.57 & .569 & -.309 & -3.38 & .001 & .065 & 0.65 & .517 & -.356 & -3.36 & .001 \\
\hline Det & -.222 & -2.45 & .014 & -.082 & -0.79 & .429 & .066 & 0.55 & .584 & -.253 & -2.94 & .003 \\
\hline Psy & -.198 & -1.81 & .071 & -.018 & -0.15 & .879 & .038 & 0.35 & .730 & -.288 & -2.63 & .008 \\
\hline Ant & .049 & 0.44 & .661 & -.262 & -2.03 & .043 & -.017 & -0.17 & .865 & -.238 & -1.95 & .051 \\
\hline Dis & -.113 & -0.97 & .334 & -.300 & -3.23 & .001 & .080 & 1.01 & .315 & -.210 & -2.18 & .029 \\
\hline \multicolumn{13}{|c|}{ Male DAS } \\
\hline Scale & (S)A2 & $t$ & $p$ & (P)A2 & $t$ & $p$ & (S)P2 & $t$ & $p$ & (P)P2 & $t$ & $p$ \\
\hline $\mathrm{N}$ & -.127 & -1.26 & .206 & -.098 & -1.07 & .284 & .004 & 0.04 & .969 & -.449 & -4.58 & .000 \\
\hline $\mathrm{E}$ & .174 & 1.35 & .177 & .083 & 0.65 & .513 & -.287 & -2.31 & .021 & .512 & 4.37 & .000 \\
\hline $\mathrm{O}$ & -.073 & -0.77 & .442 & .152 & 1.67 & .095 & -.198 & -1.63 & .104 & .519 & 5.42 & .000 \\
\hline $\mathrm{A}$ & .104 & 1.05 & .292 & .079 & 0.90 & .369 & .254 & 2.60 & .009 & .332 & 3.77 & .000 \\
\hline C & .124 & 1.36 & .173 & .239 & 2.69 & .007 & -.191 & -1.85 & .064 & .618 & 8.61 & .000 \\
\hline Nega & .004 & 0.04 & .968 & -.210 & -1.92 & .056 & -.021 & -0.20 & .843 & -.428 & -4.96 & .000 \\
\hline Det & .001 & 0.02 & .987 & -.136 & -1.73 & .083 & -.077 & -1.00 & .324 & -.437 & -5.98 & .000 \\
\hline Psy & -.126 & -1.42 & .157 & -.081 & -0.78 & .436 & -.161 & -1.18 & .237 & -.250 & -2.29 & .022 \\
\hline Ant & .157 & 1.38 & .166 & -.321 & -3.65 & .000 & -.074 & -0.75 & .451 & -.415 & -4.63 & .000 \\
\hline Dis & .058 & 0.71 & .478 & -.205 & -2.28 & .023 & .163 & 1.45 & .147 & -.510 & -6.52 & .000 \\
\hline
\end{tabular}

Note. Beta coefficients are standardized. Data in bold represent statistically significant values, $p<.05$. $(\mathrm{S}) \mathrm{A}_{1}=$ actor effect of women's self-rated personality; $(\mathrm{P}) \mathrm{A}_{1}=$ actor effect of men's rating of women's personality; $(\mathrm{S}) \mathrm{P}_{1}=$ partner effect of men's self-rated personality; $(\mathrm{P}) \mathrm{P}_{1}=$ partner effect of women's rating of men's personality; $(\mathrm{S}) \mathrm{A}_{2}$ $=$ actor effect of men's self-rated personality; $(\mathrm{P}) \mathrm{A}_{2}=$ actor effect of women's rating of men's personality; (S) $\mathrm{P}_{2}$ $=$ partner effect of women's self-rated personality; $(\mathrm{P}) \mathrm{P}_{2}=$ partner effect of men's rating of women's personality; $\mathrm{N}=$ neuroticism; $\mathrm{E}=$ extraversion; $\mathrm{O}=$ openness; $\mathrm{A}=$ agreeableness; $\mathrm{C}=$ conscientiousness; $\mathrm{Nega}=$ negative affect; Det $=$ detachment; Psy = psychoticism; Ant = antagonism; Dis = disinhibition .

When all other effects were held constant, positive actor effects were found for both partners for partner-rated conscientiousness. A positive actor effect was found for women for partner-rated openness. These results support Hypothesis 1. Negative actor effects were found for both women and men for partner-rated antagonism and disinhibition. Negative actor effects were found for women for partner-rated negative affect and for self-rated detachment. These results support Hypothesis 2 . When both self- and partner-rated personality were analyzed together, $90.9 \%$ of the significant actor effects that emerged were for relations between partner-ratings and dyadic adjustment. This supports Hypothesis 3. That is, when controlling for self-ratings, partners who were viewed as high in conscientiousness reported greater dyadic adjustment. Women who were viewed as high in openness reported greater dyadic adjustment. Furthermore, partners who were viewed as high in antagonism or disinhibition reported lower dyadic adjustment. Women who were viewed as high in negative affect reported lower dyadic adjustment. Finally, when controlling for partner-ratings, women who viewed themselves as high in detachment reported lower dyadic adjustment. Effect sizes were small to medium ranging from $|\beta|=.21(t(104)=-2.28, p=.023)$ to $|\beta|=.32(t(104)=-3.65, p<.001)$ (see Table 4 ; Cohen 1988). No actor effects were found for self-rated neuroticism, extraversion, openness, agreeableness, conscientiousness, negative affect, psychoticism, antagonism, or disinhibition when controlling for partner-ratings of these traits. No actor effects were found for partner-rated extraversion, agreeableness, detachment, or psychoticism when controlling for self-ratings of these traits. 
When all other effects were held constant, positive partner effects were found for both partners for partner-rated agreeableness and conscientiousness. Positive partner effects were found for men for self-rated agreeableness and for partner-rated extraversion and openness. These results support Hypothesis 1. Negative partner effects were found for both partners for partner-rated neuroticism, negative affect, detachment, psychoticism, and disinhibition. A negative partner effect was found for men for partner-rated antagonism. These results support Hypothesis 2. Furthermore, a negative partner effect was found for men for self-rated extraversion. When both self- and partner-rated personality were analyzed together, $85.7 \%$ of the significant partner effects that emerged were for relations between partner-ratings and dyadic adjustment. This supports Hypothesis 3 . That is, when controlling for self-ratings, women and men who rated their partner as high in agreeableness or conscientiousness reported greater dyadic adjustment. Men who rated their partner as high in extraversion or openness reported greater dyadic adjustment. Women and men who rated their partner as high in neuroticism, negative affect, detachment, psychoticism, or disinhibition reported lower dyadic adjustment. When controlling for partner-ratings, men reported greater dyadic adjustment when their partner viewed themselves as high in agreeableness. They reported lower dyadic adjustment when their partner viewed themselves as high in extraversion or antagonism. That is, while controlling for all other effects, when there was a greater difference between women's view of themselves and what men think of them on these traits, men's dyadic adjustment suffered. Effect sizes were small to large ranging from $|\beta|=.21(t(104)=-2.18, p=.029)$ to $|\beta|=.62(t(104)=8.61, p<.001)$ (see Table 4; Cohen 1988). No partner effects were found for self-rated neuroticism, openness, negative affect, detachment, psychoticism, antagonism, or disinhibition when controlling for partner-ratings of these traits.

To see whether the constraining effects found in the individual self-rated and partner-rated models replicate in the integrated model, actor and partner estimates for men were constrained for self-rated agreeableness, and partner-rated agreeableness and conscientiousness. When controlling for all other effects, constraining men's actor and partner estimates for self-rated agreeableness did not decrease model fit $\left(\Delta \chi^{2}(\Delta d f=5)=.61, p=.987\right)$. However, constraining men's actor and partner estimates for partner-rated agreeableness and conscientiousness did decrease model fit $\left(\left(\Delta \chi^{2}(\Delta d f=5)=12.80\right.\right.$, $p=.025 ;\left(\Delta \chi^{2}(\Delta d f=5)=22.55, p<.001\right.$ respectively $)$. Therefore, even after controlling for all other effects for men, men's perception of women's agreeableness and conscientiousness had a larger effect on their own dyadic adjustment than women's perception of men on these traits did.

\section{Discussion}

\subsection{Self- and Partner-Rated Personality Examined Separately}

Several personality traits significantly affected women and men's dyadic adjustment, which is in line with previous research. Neuroticism was most clearly associated with dyadic adjustment when examining both self- and partner-ratings as well as actor and partner effects. This is consistent with previous studies (Bouchard et al. 1999; Karney and Bradbury 1997). Neuroticism is defined as the tendency to experience and have trouble coping with negative emotions such as anxiety and anger (McCrae and Costa 2010). It has also been associated with mental health problems such as mood disorders (Malouff et al. 2005). Individuals who are higher on neuroticism tend to behave more negatively and have partners who behave more negatively during problem solving tasks (McNulty 2008). Therefore, individuals are less well adjusted when they view their partner as emotionally unstable. Conscientiousness was also significantly associated with dyadic adjustment for both partners in most cases. Conscientiousness is shown to increase as people age, particularly in young adulthood (Lucas and Donnellan 2009). This trait is also associated with performance of adult roles and successful adaptation to these demands. Therefore, those who exhibit these qualities and who have partners who exhibit these qualities tend to have more satisfying relationships (Watson et al. 2000). Furthermore, women's dyadic adjustment was often associated with negative affect, antagonism, and disinhibition, less frequently with agreeableness, detachment, and psychoticism, and never with extraversion. 
Men's dyadic adjustment was consistently predicted by agreeableness, detachment, and psychoticism, was often predicted by extraversion (unlike for women), negative affect and antagonism, and less frequently by disinhibition. Finally, similar to what has been previously found in the literature, both partner's dyadic adjustment was associated with men's rating of women's openness (Orth 2013). Individuals who rate high on this trait are described as being imaginative, creative, having flexible or unconventional values, and as having an interest in new activities or experiences. They may also use an intellectual approach to their perception of the world (Caspi et al. 2005). Given this project's sample being composed primarily of young professionals and university students, it is not surprising that openness to experience did show some effects on dyadic adjustment.

There were more significant predictors of men's dyadic adjustment than of women's. Overall, women and men's dyadic adjustment was more consistently predicted by negative traits than positive ones. It is not surprising to learn that self- and partner-reports of maladaptive personality traits were associated with lower dyadic adjustment. Research shows that individuals who rate higher on maladaptive personality traits are rigid, inflexible, and have difficulty adapting to social challenges which may in turn aggravate relationship issues (Johnson et al. 2004). It may be that individuals who rate higher on maladaptive personality traits seek out partners who also rate higher on these traits (Sleep et al. 2017), thereby contributing to the individual's maladjustment. Furthermore, this study's sample of participants was a community sample. Therefore, the significant negative effects underline the importance of considering subclinical personality disorder symptoms when studying couple adjustment.

With regard to positive traits, men's dyadic adjustment was more frequently associated with positive traits than women's dyadic adjustment was. Women are perceived more positively than men are because of gender stereotypes (Prentice and Carranza 2002). It may be that men show a favorable reaction to women's positive traits because both partners expect and play out these gender stereotypes.

Furthermore, as predicted, most of the significant effects came from the partner-rated models. That is, of the 53 significant effects, 32 (60\%) were from partner-rated models. Additionally, similar to previous findings (Altmann et al. 2013; Brock et al. 2016; Schaffhuser et al. 2016), effect sizes were largest for partner effects of partner-ratings. While the way individuals viewed their partner's personality played the most important role, how men viewed their partner's personality was consistently related to their own dyadic adjustment. The effects that an individual's rating of their partner's personality and that partner's rating of their own personality had on the individual's dyadic adjustment were quite different. Even though both variables measure the same thing, the effects on dyadic adjustment were markedly different. Therefore, the effects seen in the partner-rating models do not reflect actual characteristics of the partner's personality. The validity of the individual's personality judgment may have varied based on the quality of the information available to them (Funder 1995). The partners may have used their current level of dyadic adjustment as a basis for judging their partner's personality. Those who reported higher dyadic adjustment assessed their partners more favorably, and those who reported lower dyadic adjustment assessed their partners less favorably. Research shows that constructed representations, how individuals see their partners through filters driven by their ideals, predicts idealized impressions (Murray et al. 1996). For both women and men, their view of their partner's conscientiousness showed the overall strongest effect on their dyadic adjustment. Therefore, women and men who want a partner who is responsible and who view their partners as responsible tend to see an increase in their dyadic adjustment, at least among dating couples. Altogether, these results reflect the subjective perceptions of the partners rather than their objective traits.

The examination of gender revealed that is does play a role in the relationship between personality and dyadic adjustment in young couples. When examining constraints, some significant differences emerged. That is, men's dyadic adjustment was more significantly predicted by women's self-rated agreeableness than men's. It was also more significantly predicted by men's perception of women's agreeableness or conscientiousness than women's perception of men on these traits. Agreeableness involves interpersonal characteristics that foster friendly relationships with others, 
including cooperation, consideration, empathy, generosity, politeness, and kindness (McCrae and Costa 2010). Agreeableness and conscientiousness are also related in terms of their associations with responsibility, that is, being reliable and dependable (Roberts et al. 2004). They also both involve aspects of inhibition (Caspi et al. 2005). These qualities were important predictors for men's dyadic adjustment. Furthermore, gender stereotypes may explain this effect (Prentice and Carranza 2002). Young dating couples may expect women partners to be agreeable and conscientious and therefore women play out these roles while men judge them based on how well they play out these roles, which in turn influences how satisfied they are with the relationship. Men's dyadic adjustment may be projected onto their perception of their partner's personality. Furthermore, individuals, or women in this case, who rate high in agreeableness want to have positive relationships with others. Conscientiousness and agreeableness are also related to emotional control in that agreeable people try to control their expression of anger (Jensen-Campbell and Graziano 2001), for example, which may otherwise threaten the relationship. Women tend to report that they attempt to regulate negative emotions more than men do (Tobin et al. 2000) which may explain the positive effects on men's dyadic adjustment seen in this project.

\subsection{Self-and Partner-Rated Personality Analyzed Together: Integrated Model}

When self- and partner-rated personality were analyzed together in an integrated model, several significant effects disappeared. Most of the significant effects of women's and men's self-rated personality on women's dyadic adjustment were no longer significant. A somewhat similar pattern was observed in men. Most of the significant effects in the self-rating model for men were no longer significant. One new significant negative partner effect emerged. Interestingly, this was found for extraversion. It appears as though men prefer partners who rate themselves similarly to how men rate them on extraversion. That is, men may not be well adjusted when their partners rate themselves as higher on extraversion, and the opposite might be true as well. Men may not be well adjusted when their partners rate themselves as lower on extraversion and as therefore lacking outgoing and social characteristics. Furthermore, some of the significant actor effects and all of the significant partner effects of partner-reported personality on men's dyadic adjustment remained in the integrated model. While each partner's view of the other's personality played the most important role, men's view of women's personality was consistently related to their own dyadic adjustment. Finally, similar to results in the separate models, effect sizes were largest for partner effects of partner-ratings, particularly for men's partner effects of partner-ratings (i.e., the effect of men's view of women's personality on men's dyadic adjustment), with men's rating of women's conscientiousness having the largest effect. Individuals high on conscientiousness are typically more goal-oriented, better at following norms and rules, and are better at controlling their impulses (Roberts et al. 2009). This study's sample was comprised largely of young professionals and students who often require these characteristics to be successful, and it can be assumed that an individual in their twenties wants a partner who has these qualities. Furthermore, with regard to negative traits, disinhibition, related to the extreme negative expression of conscientiousness, was most consistently associated with dyadic adjustment. That is, individuals who were perceived as and who perceived their partner as tending to prefer immediate gratification, a lack of consideration for past mistakes, and impulsive behavior (Decuyper et al. 2018), also reported dissatisfaction.

When reproducing constraints from the separate models, some significant differences remain in the integrated model. Even after all other effects were held constant, men's perception of women's agreeableness and conscientiousness had a larger effect on men's dyadic adjustment than women's perception of men on these traits did. Although men did rate women's agreeableness and conscientiousness to be higher than theirs, women's partner-rated agreeableness and conscientiousness were still within the average of what is expected in adults. Nonetheless, the men in this sample greatly appreciated having a partner who exhibited characteristics of these traits. 
Overall, the results demonstrate significant evidence for the incremental predictive effects of partner-rated personality on dyadic adjustment, especially for partner effects (i.e., the effect of an individual's perception of their partner's personality on their own dyadic adjustment). That is, of the 32 significant effects in the integrated model, $28(87.5 \%)$ were of partner-ratings, 18 ( $56.25 \%$ total, $64.29 \%$ of partner-ratings) of which were partner effects. In other words, with regard to personality, the most important factor for dyadic adjustment is how individuals perceive their partner. The results from this study can have important implications for couple therapists and the development of intervention strategies. Marital therapists are increasingly addressing personality characteristics with the belief that these characteristics are associated with distress and affect the outcomes of couple therapy (Gattis et al. 2004). Previous research mainly focuses on couples who have been together for several years and who are married. The current research focused on young dating couples and is therefore informative of the earlier stages of relationships. Therapists benefit from understanding how partners view each other and from knowing what personality traits predict successful relationships. If they understand how personality predicts dyadic adjustment at the beginning of relationships, it may be easier for them to intervene and help couples minimize or avoid rigid and dysfunctional patterns rather than try to work on them later. Couple therapy research demonstrates that couples continue to influence each other over the course of treatment (Cook and Snyder 2005). With couples gaining insight into how their personality patterns predict relationship dysfunction, they can become more sensitive to one another and respond more appropriately, thereby reducing conflict. Furthermore, personality trait ratings change more quickly in therapy than once thought, with these changes shown to maintain over time (Roberts et al. 2017). These results help clinicians tailor their treatments to address specific traits with high fidelity. Furthermore, addressing individuals' interpretations of their partners' personality characteristics, rather than simply assessing actual characteristics, can have significant implications for the ways in which couple therapists intervene.

\subsection{Limitations}

Some limitations should be taken into account when interpreting the findings. First, the study is cross-sectional which therefore makes it not possible to discuss conclusions about causality. Future longitudinal studies will be able to address this issue and will further our understanding of the temporal direction between personality traits and dyadic adjustment. Most couples in this study have agreed to be contacted at a later date in order for there to be follow-up with regard to their couple status, personality traits, and dyadic adjustment if they are still in a relationship. A second limitation of the present study has to do with the generalizability of results. Only heterosexual couples were recruited for this study. Personality traits may play a different role in their relationship with dyadic adjustment in same-sex couples. Research shows that homosexual and heterosexual individuals differ significantly on several Big Five traits, the strongest of which is for openness to experience (Lippa 2005). It may be that our overall results would change if same-sex couples were included in the sample because there may be differences in these couples. Therefore, the current results may not align with those from same-sex couples. There are some studies that demonstrate the indirect effects of personality on relationship quality (e.g., Clausell and Roisman 2009). However, there are no known studies on the direct effect of personality traits on couple satisfaction in same-sex couples. Furthermore, the sample in this study remains relatively small. The participating couples are also quite satisfied overall, reducing the likelihood of finding small effects. Additional research using larger representative population samples will allow for more generalizable results. Moreover, research on relationships may create selection effects. The sample in this project consisted of volunteers. Research volunteers are shown to be significantly higher in conscientiousness than nonvolunteers (Lonnqvist et al. 2007), which may be explained by their sense of duty (McCrae and Costa 2010). Therefore, the incidence of conscientiousness may have played a role in couples' desire to spend time and effort to act as research participants and in their dyadic adjustment. Furthermore, participants who decide to participate in these types of studies may be more motivated to learn about and understand their relationship than 
the general population. Couples who are very well or very poorly adjusted may be more willing to seek out and participate. Research shows that respondents are higher in extraversion, agreeableness, and conscientiousness, and lower in neuroticism. This indicates that research volunteers are more psychologically adjusted than individuals who choose not to participate. Furthermore, the sample in this project consisted largely of young professionals and university students. These occupations demand qualities of self-control and achievement motivation. Those who are at the beginning of their career may strive for high standards and be persistent and determined in their pursuit of their goals. In their relationships, they may be better able to generate strategies for handling social conflicts and other emotionally arousing experiences. However, offering a monetary incentive may render the study more attractive and more difficult to refuse. Nevertheless, the monetary incentive in this study was judged appropriate (e.g., covers cost of travel and parking in downtown Montreal) by the ethics committee. Finally, future research that includes self-reports of behavior as well as the assessment of actual behaviors are needed to corroborate the results.

\subsection{Conclusions}

Despite these limitations, this study contributes to the existing literature on the association between personality traits and dyadic adjustment in several ways. The sampling of only dating couples in a limited age-range represents a strength of this study. Previous studies mostly use dating and/or married couples across a large age-range making it difficult to map the progression of personality and the effects it can have on dyadic adjustment across time and couple type. This study is part of a bigger project that will follow participants in time and that will also include married couples. This will allow for the direct comparison of dating and married couples with regard to personality trait expression and relation to dyadic adjustment. It will also allow for the examination of changes in personality trait expression across time, and which personality traits contribute to relationship termination, maintenance, or transition to marriage. The study also used both self- and partner-ratings of personality to get a more complete picture of the relationship between personality and dyadic adjustment. Furthermore, the use of APIM models allowed for the consideration of the dyadic nature of the data, and the study also included an integrated APIM to examine the incremental predictive utility of partner-reports. Moreover, personality was assessed using two dimensional models that span the normal-abnormal spectrum and the study is among the first to address associations between maladaptive personality traits using the maladaptive personality trait model and dyadic adjustment.

Supplementary Materials: The following are available online at http://www.mdpi.com/2076-0760/8/10/271/s1, Table S1: Correlation matrix for women and men's self-rated personality, Table S2: Correlation matrix for women's self-rated personality and men's partner-rated personality, Table S3: Correlation matrix for women's partner-rated personality and men's self-rated personality, Table S4: Correlation matrix for women and men's partner-rated personality.

Author Contributions: Conceptualization, E.S. and G.E.-B.; Data curation, E.S., A.G. and G.E.-B.; Formal analysis, E.S., H.L. and G.E.-B.; Funding acquisition, E.S. and G.E.-B.; Investigation, E.S., A.G. and G.E.-B.; Methodology, E.S., H.L. and G.E.-B.; Project administration, E.S. and G.E.-B.; Resources, E.S. and G.E.-B.; Supervision, E.S. and G.E.-B.; Validation, Evelyne Smith, H.L. and G.E.-B.; Visualization, E.S. and G.E.-B.; Writing-original draft, E.S., A.G., H.L. and G.E.-B.; Writing-review \& editing, E.S. and G.E.-B.

Funding: This research was funded by the Social Sciences and Humanities Research Council (SSHRC), grant number 430-2016-00950.

Conflicts of Interest: The authors declare no conflict of interest.

\section{References}

Altmann, Tobias, Susan Sierau, and Marcus Roth. 2013. I Guess You're Just Not My Type Personality Types and Similarity between Types as Predictors of Satisfaction in Intimate Couples. Journal of Individual Differences 34: 105-17. [CrossRef] 
Anderson, Jaime, Martin Sellbom, and Randall Salekin. 2018. Utility of the Personality Inventory for DSM-5-Brief Form (PID-5-BF) in the measurement of maladaptive personality and psychopathology. Assessment 25: 596-607. [CrossRef] [PubMed]

Ashton, Michael, and Kibeom Lee. 2001. A theoretical basis for the major dimensions of personality. European Journal of Personality 15: 327-53. [CrossRef]

Bach, Bo, Jessica Maples-Keller, Sune Bo, and Erik Simonsen. 2016. The alternative DSM-5 personality disorder traits criterion: A comparative examination of three self-report forms in a Danish population. Personality Disorders 7: 124-35. [CrossRef] [PubMed]

Baillargeon, Jacques, Gilles Dubois, and René Marineau. 1986. Traduction francaise de l'Echelle d'ajustement dyadique. Canadian Journal of Behavioural Science 18: 25-34. [CrossRef]

Block, Jack. 1995. A contrarian view of the Five-Factor approach to personality description. Psychological Bulletin 117: 187-215. [CrossRef] [PubMed]

Botwin, Michael, David Buss, and Todd Shackelford. 1997. Personality and Mate Preferences—Five Factors In Mate Selection and Marital Satisfaction. Journal of Personality 65: 107-36. [CrossRef]

Bouchard, Geneviève, Yvan Lussier, and Stéphane Sabourin. 1999. Personality and Marital Adjustment: Utility of the Five-Factor Model of Personality. Journal of Marriage and the Family 61: 651-60. [CrossRef]

Brock, Rebecca, Lilian Dindo, Leonard Simms, and Lee Anna Clark. 2016. Personality and dyadic adjustment: Who you think your partner is really matters. Journal of Family Psychology 30: 602-13. [CrossRef]

Caspi, Avshalom, Brent Roberts, and Rebecca Shiner. 2005. Personality development: stability and change. Annual Review of Psychology 56: 453-84. [CrossRef]

Clausell, Eric, and Glenn Roisman. 2009. Outness, Big Five personality traits, and same-sex relationship quality. Journal of Social and Personality Relationships 26: 211-26. [CrossRef]

Claxton, Amy, Norm O' Rourke, JuliAnna Smith, and Anita DeLongis. 2012. Personality traits and marital satisfaction within enduring relationships: An intra-couple discrepancy approach. Journal of Social and Personal Relationships 29: 375-96. [CrossRef]

Cohen, Jacob. 1988. Statistical Power Analysis for the Behavioral Sciences, 2nd ed. Hillsdale: Lawrence Earlbaum Associates.

Cook, William, and David Kenny. 2005. The Actor-Partner Interdependence Model: A model of bidirectional effects in developmental studies. International Journal of Behavioral Development 29: 101-9. [CrossRef]

Cook, William, and Douglas Snyder. 2005. Analyzing nonindependent outcomes in couple therapy using the actor-partner interdependence model. Journal of Family Psychology 19: 133-41. [CrossRef] [PubMed]

Daspe, Marie-Ève, Stéphane Sabourin, Katherine Peloquin, Yvan Lussier, and John Wright. 2013. Curvilinear associations between neuroticism and dyadic adjustment in treatment-seeking couples. Journal of Family Psychology 27: 232-41. [CrossRef] [PubMed]

Decuyper, Mieke, Marlene De Bolle, and Filip De Fruyt. 2012. Personality similarity, perceptual accuracy, and relationship satisfaction in dating and married couples. Personal Relationships 19: 128-45. [CrossRef]

Decuyper, Mieke, Fien Gistelinck, Jasmine Vergauwe, Gina Pancorbo, and Filip De Fruyt. 2018. Personality pathology and relationship satisfaction in dating and married couples. Personality Disorders: Theory, Research, and Treatment 9: 81-92. [CrossRef]

Digman, John. 1997. Higher-order factors of the Big Five. Journal of Personality and Social Psychology 73: 1246-56. [CrossRef]

Dyrenforth, Portia, Deborah Kashy, Brent Donnellan, and Richard Lucas. 2010. Predicting Relationship and Life Satisfaction from Personality in Nationally Representative Samples from Three Countries: The Relative Importance of Actor, Partner, and Similarity Effects. Journal of Personality and Social Psychology 99: 690-702. [CrossRef]

Fossati, Andrea, Antonella Somma, Serena Borroni, Kristian Markon, and Robert Krueger. 2017. The Personality Inventory for DSM-5 Brief Form: Evidence for reliability and construct validity in a sample of communitydwelling Italian adolescents. Assessment 24: 615-31. [CrossRef]

Funder, David. 1995. On the Accuracy of Personality Judgment-A Realistic Approach. Psychological Review 102: 652-70. [CrossRef]

Furler, Katrin, Veronica Gomez, and Alexander Grob. 2014. Personality perceptions and relationship satisfaction in couples. Journal of Research in Personality 50: 33-41. [CrossRef] 
Gattis, Krista, Sara Berns, Lorelei Simpson, and Andrew Christensen. 2004. Birds of a feather or strange birds? Ties among personality dimensions, similarity, and marital quality. Journal of Family Psychology 18: 564-74. [CrossRef]

Geist, Robert, and David Gilbert. 1996. Correlates of expressed and felt emotion during marital conflict- Satisfaction, personality, process, and outcome. Personality and Individual Differences 21: 49-60. [CrossRef]

Gore, Whitney, and Thomas Widiger. 2013. The DSM-5 dimensional trait model and five-factor models of general personality. Journal of Abnormal Psychology 122: 816-21. [CrossRef]

Guenole, Nigel. 2015. The hierarchical structure of work-related maladaptive personality traits. European Journal of Psychological Assessment 31: 83-90. [CrossRef]

Hinshaw, Stephen, and Andrea Stier. 2008. Stigma as related to mental disorders. Annual Review of Clinical Psychology 4: 367-93. [CrossRef]

Hogan, Robert, and Joyce Hogan. 1997. Hogan Development Survey Manual. Tulsa: Hogan Assessment Systems.

Hogan, Robert, and Joyce Hogan. 2001. Assessing leadership: A view from the dark side. International Journal of Selection and Assessment 9: 40-51. [CrossRef]

Jensen-Campbell, Lauri, and William Graziano. 2001. Agreeableness as a Moderator of Interpersonal Conflict. Journal of Personality 69: 323-62. [CrossRef]

Johnson, Jeffrey, Henian Chen, and Patricia Cohen. 2004. Personality disorder traits during adolescence and relationships with family members during the transition to adulthood. Journal of Consulting and Clinical Psychology 72: 923-32. [CrossRef]

Jones, Daniel, and Delroy Paulhus. 2014. Introducing the Short Dark Triad (SD3): A brief measure of Dark personality traits. Assessment 21: 28-41. [CrossRef]

Karney, B. R., and T. N. Bradbury. 1997. Neuroticism, marital interaction, and the trajectory of marital satisfaction. Journal of Personality and Social Psychology 72: 1075-92. [CrossRef]

Karney, Benjamin, and Thomas Bradbury. 2000. Attributions in marriage: State or trait? A growth curve analysis. Journal of Personality and Social Psychology 78: 295-309. [CrossRef]

Karney, Benjamin, Thomas Bradbury, Frank Finchman, and Kieran Sullivan. 1994. The role of negative affectivity in the association between attributions and marital satisfaction. Journal of Personality and Social Psychology 66: 413-24. [CrossRef]

Kashy, Deborah, and David Kenny. 2000. The analysis of data from dyads and groups. In Handbook of Research Methods in Social and Personality Psychology. Edited by Harry T. Reis and Charles M. Judd. Cambridge: Cambridge University Press.

Kenny, David. 1996. Models of Non-Independence in Dyadic Research. Journal of Social and Personal Relationships 13: 279-94. [CrossRef]

Kenny, David, and William Cook. 1999. Partner effects in relationship research- Conceptual issues, analytic difficulties, and illustrations. Personal Relationships 6: 433-48. [CrossRef]

Kenny, David, Deborah Kashy, and William Cook. 2006. Dyadic Data Analysis. New York: Guilford Press.

Kosek, Robert. 1996. The Quest for a Perfect Spouse: Spousal Ratings and Marital Satisfaction. Psychological Reports 79: 731-35. [CrossRef]

Krueger, Robert, and Nicholas Eaton. 2010. Personality traits and the classification of mental disorders: toward a more complete integration in DSM-5 and an empirical model of psychopathology. Personality Disorders: Theory, Research, and Treatment 1: 97-118. [CrossRef]

Krueger, Robert, Jaime Derringer, Kristian Markon, David Watson, and Andrew Skodol. 2012. Initial construction of a maladaptive personality trait model and inventory for DSM-5. Psychological Medicine 42: 1879-90. [CrossRef]

Krueger, Robert, Jaime Derringer, Kristian Markon, David Watson, and Andrew Skodol. 2013. The Personality Inventory for DSM-5—Brief Form (PID-5-BF)—Adult. Washington, DC: American Psychiatric Association.

Lippa, Richard. 2005. Sexual Orientation and Personality. Annual Review of Sex Research 16: 110-53.

Lonnqvist, Jan-Erik, Sampo Paunonen, Markku Verkasalo, Sointu Leikas, Annamari Tuulio-Henriksson, and Jouko Lonnqvist. 2007. Personality characteristics of research volunteers. European Journal of Personality 21: 1017-30. [CrossRef]

Lucas, Richard, and Brent Donnellan. 2009. Age differences in personality: evidence from a nationally representative Australian sample. Developmental Psychology 45: 1353-63. [CrossRef] 
Malouff, John, Einar Thorsteinsson, and Nicola Schutte. 2005. The Relationship between the Five-Factor Model of Personality and Symptoms of Clinical Disorders: A Meta-Analysis. Journal of Psychopathology and Behavioral Assessment 27: 101-14. [CrossRef]

Malouff, John, Einar Thorsteinsson, Nicola Schutte, Navjot Bhullar, and Sally Rooke. 2010. The Five-Factor Model of personality and relationship satisfaction of intimate partners: A meta-analysis. Journal of Research in Personality 44: 124-27. [CrossRef]

Markon, Kristian, Lena Quilty, Michael Bagby, and Robert Krueger. 2013. The development and psychometric properties of an informant-report form of the personality inventory for DSM-5 (PID-5). Assessment 20: 370-83. [CrossRef]

McCrae, Robert. 1991. The five-factor model and its assessment in clinical settings. Journal of Personality Assessment 57: 399-414. [CrossRef]

McCrae, Robert, and Paul Costa. 1987. Validation of the Five-Factor Model of Personality across Instruments and Observers. Journal of Personality and Social Psychology 52: 81-90. [CrossRef]

McCrae, Robert, and Paul Costa. 1997. Personality Trait Structure as a Human Universal. American Psychologist 52: 509-16. [CrossRef]

McCrae, Robert, and Paul Costa. 2010. NEO Inventories for the NEO Personality Inventory-3 (NEO-PI-3, NEO Five-Factor Inventory-3 (NEO-FFI-3), NEO Personality Inventory-Revised (NEO-PI-R) Professional Manual. Lutz: Psychological Assessment Resources (PAR).

McCrae, Robert, and Paul Costa. 2013. Introduction to the empirical and theoretical status of the Five-Factor Model of personality traits. In Personality Disorders and the Five-Factor Model of Personality, 3rd ed. Edited by Thomas A. Widiger and Paul T. Costa. Washington, DC: American Psychological Association, pp. 15-27.

McNulty, James. 2008. Neuroticism and interpersonal negativity: the independent contributions of perceptions and behaviors. Personality and Social Psychology Bulletin 34: 1439-50. [CrossRef]

Murray, Sandra, John Holmes, and Dale Griffin. 1996. The benefits of positive illusions- Idealization and the construction of satisfaction in close relationships. Journal of Personality and Social Psychology 70: 79-98. [CrossRef]

Muthén, Linda, and Bengt Muthén. 2017. Mplus User's Guide, 8th ed. Los Angeles: Muthén \& Muthén.

Nestadt, Gerald, Paul Costa Jr., Fang-Chi Hsu, Jack Samuels, Joseph Bienvenu, and William Eaton. 2008. The relationship between the five-factor model and latent Diagnostic and Statistical Manual of Mental Disorders, Fourth Edition personality disorder dimensions. Comprehensive Psychiatry 49: 98-105. [CrossRef]

Oltmanns, Thomas, Eric Turkheimer, and Milton Strauss. 1998. Peer Assessment of Personality Traits and Pathology in Female College Students. Assessment 5: 53-65. [CrossRef]

Orth, Ulrich. 2013. How large are actor and partner effects of personality on relationship satisfaction? The importance of controlling for shared method variance. Personality and Social Psychology Bulletin 39: 1359-72. [CrossRef]

Ozer, Daniel, and Verónica Benet-Martinez. 2006. Personality and the prediction of consequential outcomes. Annual Review of Psychology 57: 8.1-8.21. [CrossRef]

Paulhus, Delroy, and Kevin Williams. 2002. The Dark Triad of personality: Narcissism, Machiavellianism, and psychopathy. Journal of Research in Personality 36: 556-63. [CrossRef]

Prentice, Deborah, and Erica Carranza. 2002. What Women and Men Should Be, Shouldn't be, are Allowed to be, and don't Have to Be-The Contents of Prescriptive Gender Stereotypes. Psychology of Women Quarterly 26: 269-81. [CrossRef]

Roberts, Brent, and Avshalom Caspi. 2001. Personality development and the person-situation debate-It's déjà vu all over again. Psychological Inquiry 12: 104-9. [CrossRef]

Roberts, Brent, Tim Bogg, Kate Walton, Oleksandr Chernyshenko, and Stephen Stark. 2004. A lexical investigation of the lower-order structure of conscientiousness. Journal of Research in Personality 38: 164-78. [CrossRef]

Roberts, Brent, Kate Walton, and Wolfgang Viechtbauer. 2006. Patterns of mean-level change in personality traits across the life course: a meta-analysis of longitudinal studies. Psychological Bulletin 132: 1-25. [CrossRef]

Roberts, Brent, Joshua Jackson, Jennifer Fayard, Grant Edmonds, and Jenna Meints. 2009. Conscientiousness. In Handbook of Individual Differences in Social Behavior. Edited by Mark R. Leary and Rick H. Hoyle. New York: Guilford Press, pp. 369-81.

Roberts, Brent, Jing Luo, Daniel Briley, Philip Chow, Rong Su, and Patrick Hill. 2017. A systematic review of personality trait change through intervention. Psychological Bulletin 143: 117-41. [CrossRef] 
Robins, Richard, Avshalom Caspi, and Terrie Moffitt. 2000. Two Personalities, One Relationship—Both Partners' Personality Traits Shape the Quality of Their Relationship. Journal of Personality and Social Psychology 79: 251-59. [CrossRef]

Samuel, Douglas, and Thomas Widiger. 2006. Clinicians' judgments of clinical utility: a comparison of the DSM-IV and five-factor models. Journal of Abnormal Psychology 115: 298-308. [CrossRef]

Sanderson, Cynthia, and John Clarkin. 2002. Further use of the NEO PI-R personality dimensions in differential treatment planning. In Personality Disorders and the Five-Factor Model of Personality, 2nd ed. Edited by Paul T. Costa and Thomas A. Widiger. Washington, DC: American Psychological Association, pp. 351-75.

Schaffhuser, Kathrin, Mathias Allemand, and Mike Martin. 2014. Personality Traits and Relationship Satisfaction in Intimate Couples: Three Perspectives on Personality. European Journal of Personality 28: 120-33. [CrossRef]

Schaffhuser, Kathrin, Mathias Allemand, Christina Werner, and Mike Martin. 2016. Discrepancy in Personality Perceptions Is Related to Relationship Satisfaction: Findings from Dyadic Latent Discrepancy Analyses. Journal of Personality 84: 658-70. [CrossRef]

Seiffge-Krenke, Inge. 2003. Testing theories of romantic development from adolescence to young adulthood: Evidence of a developmental sequence. International Journal of Behavioral Development 27: 519-31. [CrossRef]

Sleep, Chelsea, Justin Lavner, and Joshua Miller. 2017. Do individuals with maladaptive personality traits find these same traits desirable in portential romantic partners? Personality and Individual Differences 119: 317-22. [CrossRef]

South, Susan, Eric Turkheimer, and Thomas Oltmanns. 2008. Personality disorder symptoms and marital functioning. Journal of Consulting and Clinical Psychology 76: 769-80. [CrossRef]

Spanier, Graham. 1976. Measuring Dyadic Adjustment: New Scales for Assessing the Quality of Marriage and Similar Dyads. Journal of Marriage and the Family 38: 15-28. [CrossRef]

Tobin, Renée, William Graziano, Eric Vanman, and Louis Tassinary. 2000. Personality, Emotional Experience, and Efforts to Control Emotions. Journal of Personality and Social Psychology 79: 656-69. [CrossRef]

Watson, David, Brock Hubbard, and David Wiese. 2000. General traits of personality and affectivity as predictors of satisfaction in intimate relationships-Evidence from self- and partner-ratings. Journal of Personality 68 : 413-49. [CrossRef]

Widiger, Thomas, John Livesley, and Lee Anna Clark. 2009. An integrative dimensional classification of personality disorder. Psychological Assessment 21: 243-55. [CrossRef]

Widiger, Thomas, Paul Costa, Whotney Gore, and Cristina Crego. 2013. Five-Factor Model personality disorder research. In Personality Disorders and the Five-Factor Model of Personality, 3rd ed. Edited by Thomas A. Widiger and Paul T. Costa. Washington, DC: American Psychological Association, pp. 75-100. 